\title{
Opinion Article
}

\section{Phage Therapy in Bacterial Infection}

\author{
Hossain Uddin Shekhar* \\ Department of Biochemistry and Molecular Biology, Dhaka University, Dhaka-1000, Bangladesh
}

*Corresponding author: Hossain Uddin Shekhar, Department of Biochemistry and Molecular Biology, Dhaka University, Dhaka-1000, Bangladesh.
Received Date: February 02, 2021

Published Date: March 24, 2021

\section{Opinion}

Phage therapy has proven to be an effective method to control bacterial infection [1] and it has been successfully applied for the treatment of Shigella dysenteriae infections in children. The phage therapy approach is an effective method for controlling multidrug-resistant bacteria. Félix d'Herelle discovered phages as a lytic agent active on dysentery bacteria exactly 100 years ago [2]. When working on cholera in India, d'Herelle observed that mortality declines during an epidemic. Studying stool phages, he linked death and recovery from disease with the absence or presence, respectively, of virulent vibriophages in the patients [3]. Shigellosis, an infectious diarrheal disease, is caused by the enteric pathogen Shigella. It is a major worldwide health burden and causes nearly 164.7 million cases and over a million deaths every year, most of them occurring in developing countries [4]. Bacteriophages (phages) are viruses that infect bacteria. With many species of bacteria becoming resistant to antibiotics, phages are reemerging as an attractive alternative and have already been used to combat a wide variety of bacterial infections [5]. One of the first bacteriophages ever isolated was a Shigella phage, discovered by Felix d'Herelle in 1917 [6,7], which was subsequently shown to cure children suffering from severe S. dysenteriae infection [8]. However, relatively few studies on the isolation or characterization of Shigella phages have been performed since then. Information for only $~ 35$ Shigella phages has been deposited in public databases, and detailed studies of these phages are sparse. By contrast, over 400 Escherichia and Salmonella phages are readily available, some of which, such as $\phi X 174, \mathrm{P} 22, \lambda$, and T4, have been used as model systems for decades. As the problem of antibiotic resistance becomes ever more acute, a number of scientists and clinicians are looking again at bacteriophages as a therapeutic option in the treatment of bacterial infections.

The researchers used phages adapted to the intestine of guinea pigs, arguing that laboratory-adapted phages had lost major traits for in vivo replication in the human gut [9]. In contrast, researchers from the Dhaka cholera hospital used massive doses of brothpropagated phage (1015 pfu) for the treatment of acute cholera, which necessitated large production facilities. Such a high dose was chosen to achieve an immediate 'lysis from without' of the high titers of vibrios measured in cholera 'rice stool.' The researchers reasoned that the replication time of vibriophage was longer than the gut transit time through the cholera patient (30 min). Phage treatment significantly reduced the stool output compared to controls, but had only a weak effect on the duration of diarrhea. Antibiotic treatment with tetracycline was clinically much more efficient than phage [10]. In addition, Soviet scientists conducted in 1971 a phage treatment trial of cholera in Dhaka. Oral phage alone or combined with intramuscularly injected phage had no impact on diarrhea duration, stool volume, or vibrio excretion compared to placebo, while tetracycline caused a marked amelioration [11]. Faruque et al. [12] isolated a phage from surface water samples from Bangladesh that specifically lyses strains of S. dysenteriae type 1 . This phage, designated SF-9, belongs to the Podoviridae family and has a 41-kb double-stranded DNA genome. Water samples were tested to determine the prevalence of SF-9, and the results indicated that 9 of $71(12.6 \%)$ water samples were positive for the phage. The authors concluded that phage SF-9 may have epidemiological applications as an index of the presence of S. dysenteriae type 1 in environmental waters. Another attempt to treat human shigellosis 
with phages was made by the Hirszfeld Institute in 1957. The Institute was instrumental in developing and producing phages for the treatment of many diseases, including infections caused by antibiotic resistant bacteria that were refractory to conventional treatment with antibiotics [13]. Phage therapy will not be a panacea, but it is likely that it will find application in infections where favorable conditions are met.

\section{Acknowledgement}

None.

\section{Conflicts of Interest}

No conflicts of interest.

\section{References}

1. Sulakvelidze A, Alavidze Z, Morris JG (2001) Bacteriophage therapy. Antimicrob Agents Chemother 45(3): 649-659.

2. D Herelle F (1917) On an invisible microbe that is an antagonist of dysenteric bacilli. C R Acad Sci Paris 165: 373-375.

3. D Herelle F (1929) Studies upon Asiatic cholera. Yale J Biol Med 1(4): 195-219.

4. Kotloff KL, Winickoff JP, Ivanoff B, Clemens JD, Swerdlow DL, et al. (1999) Global burden of Shigella infections: implications for vaccine development and implementation of control strategies. Bull. World Health Organ. 77(8), 651-666.
5. Abedon ST, Kuhl SJ, Blasdel BG, Kutter EM (2011) Phage treatment of human infections. Bacteriophage 1(2): 66-85.

6. D Herelle F (1917) An invisible antagonist microbe of dysentery bacillus. C R Hebd Seances Acad Sci 165: 373-375.

7. Note by MF d Herelle (2011) On an invisible microbe antagonistic to dysentery bacilli. Note by MF d Herelle, presented by M Roux Comptes Rendus Academie des Sciences 1917 165: 373-755.

8. D Herelle F (1931) Bacteriophage as a treatment in acute medical and surgical infections. Bull NY Acad Med 7(5): 329-348.

9. Sayamov RM (1963) Treatment and prophylaxis of cholera with bacteriophage. Bull WHO. 28(3): 361-367.

10. Monsur KA, Rahman MA, Huq F, M N Islam, R S Northrup, et al. (1970) Effect of massive doses of bacteriophage on excretion of vibrios, duration of diarrhoea and output of stools in acute cases of cholera. Bull World Health Organ. 42(5): 723-732.

11. Marcuk LM, Nikiforov VN, Scerbak JF, T A Levitov, RI Kotljarova, et al. (1971) Clinical studies of the use of bacteriophage in the treatment of cholera. Bull World Health Organ 45(1): 77-83.

12. Faruque SM, Chowdhury N, Khan R, Hasan MR, Nahar J, et al. (2003) Shigella dysenteriae type 1-specific bacteriophage from environmental waters in Bangladesh. Appl Environ Microbiol 69(12): 7028-7031.

13. Sulakvelidze A, Alavidze Z, Morris JG (2001) Bacteriophage therapy. Antimicrob Agents Chemother 45(13): 649-59. 